\title{
Congenital glaucoma in the West Bank and Gaza Strip
}

\author{
Mark J Elder
}

\begin{abstract}
This study presents the results of all patients with congenital glaucoma who were managed at St John Ophthalmic Hospital, Jerusalem from 1981 to 1990 . This involved 118 eyes, 174 surgical procedures, and 460 examinations under anaesthesia. All procedures showed decreasing success rates with time. However, trabeculectomy was clearly the most successful in the hands of general ophthalmologists. Careful, long term follow up with particular regard to both intraocular pressure and detection and treatment of amblyopia are emphasised.

(Brf Ophthalmol 1993; 77: 413-416)
\end{abstract}

Congenital glaucoma is four times more common in the Middle East ${ }^{1}$ compared with Western societies, with an incidence of 1:2500 live births, ${ }^{1}$ and in Saudi Arabia it is responsible for $16 \%$ of all blindness in children. ${ }^{2}$ Current surgical techniques for controlling intraocular pressure (IOP) in congenital glaucoma include goniotomy, trabeculotomy ab externo, and trabeculectomy. The reported success in Western societies for each of these procedures is more than $80 \% .^{3-13}$ However, this contrasts with the results in the Middle East. ${ }^{14}$

This retrospective study reports the long term results in 118 eyes of 67 infants who presented with congenital glaucoma over a 10 year period. All infants were less than 1 year old at presentation and mean follow up was 43.9 months.

The St John Ophthalmic Hospital, Jerusalem is an 82 bed ophthalmic hospital and is essentially the only institution that offers ocular surgery, under general anaesthesia, to the $1 \cdot 7$ million Palestinian Arabs of the occupied territories of the West Bank and Gaza Strip. Therefore, the patients in this study comprise the majority of children with congenital glaucoma within the territories with the exception of those patients who sought an ophthalmic opinion in another country. The patients were managed by ex-patriot and local Palestinian doctors with qualifications of FCOphth or FRACO or similar. All doctors were general ophthalmologists and no one had special, postfellowship glaucoma training.

St John Ophthalmic Hospital, PO Box 19960, Jerusalem, Israel M J Elder

Correspondence to: Mark Elder, 1 Grosvenor Crescent, London SW1X 7EF.

Accepted for publication 19 February 1993

\section{Patients and methods}

Patients who were selected for this study had all presented to the St John Ophthalmic Hospital with congenital glaucoma before the age of 12 months. The study period was from January 1981 to December 1990 and case record retrieval was $93 \%$.

From the case records, the patient's age, family history, main presenting features, ocular abnormalities, and systemic abnormalities were noted. Most patients had a paediatric assessment. From the examination under anaesthesia particular regard was given to horizontal corneal diameter, corneal clarity, IOP (Perkins handheld tonometer and Schiotz tonometer), funduscopy, and retinoscopy. Follow up examinations included a combination of examination under anaesthesia and examination in clinic, supplemented with orthoptic assessments, cycloplegic refractions, and B scan sonography.

The surgical techniques used for trabeculectomy, trabeculotomy ab externo, and goniotomy were those of Cairns, ${ }^{15}$ McPherson, ${ }^{7}$ and Barkan $^{34}$ respectively. For trabeculotomy $a b$ externo Harms trabeculotomes were used and in $7 / 57(12 \%)$ a scleral flap was not raised but this did not seem to influence success. All eyes received antibiotic steroid drops for approximately 2 weeks. No eye received pilocarpine drops postoperatively.

Surgical success was defined as an IOP of less than $21 \mathrm{~mm} \mathrm{Hg}$ without medication. The data are presented using actuarial estimates (life table method) and compared using the MantelHaenszel procedure. ${ }^{1617}$

\section{Results}

During the 10 year study period, 72 patients presented under the age of 12 months with congenital glaucoma. Five sets of notes were unavailable for examination but otherwise no patient was excluded from this study. The study group involved 67 patients, 118 eyes, and 174 surgical procedures. Sixteen patients had unilateral glaucoma, the right eye being involved in 10/16 cases; 22 of 67 patients (33\%) presented before the age of 1 month; and 52/67 patients (78\%) presented within the first 6 months of life. The age of presentation was similar in the group with unilateral glaucoma, with $12 / 16$ patients (75\%) presenting within 6 months.

Follow up ranged from 1 to 120 months with a mean of 43.9 (SD 34.2) months. A subgroup of patients was defined as those with more than 36 months of follow up and this involved 58 eyes of 31 patients with follow up ranging from 37 to 120 months with a mean of $76 \cdot 0$ (SD $26 \cdot 0$ ) months.

A family history was present in $9 / 67$ patients (13\%). No parent or grandparent had congenital glaucoma but one patient had an uncle with bilateral congenital glaucoma and mental retardation. A history of consanguinity was present in $33 / 67$ patients ( $49 \%$ ). The main reason for presentation was that of cloudy corneas, being present in $89 / 118$ eyes $(75 \%)$. Other primary reasons for referral included enlarged eyes $21 / 118(18 \%)$, watery eyes $3 / 118$, photo- 
Table 1 Ocular abnormalities at presentation

\begin{tabular}{lr}
\hline Type of glaucoma & \\
Isolated trabeculodysgenesis & 111 \\
Iridotrabeculodysgenesis & 4 \\
Corneodysgenesis & 3 \\
\cline { 2 - 2 } & 118 \\
Abnormalities present in unilateral glaucoma patients & 1 \\
Choroidal haemangioma (Sturge Weber syndrome) & 1 \\
Posterior polar cataract & 1 \\
Peter's anomaly & 2 \\
Abnormalities present in bilateral glaucoma patients & 2 \\
Bilateral congenital cataracts & 1 \\
Bilateral spherophakia & \\
Bilateral macular scarring (unknown aetiology) & \\
\hline
\end{tabular}

Table 2 Surgical complications

\begin{tabular}{ll}
\hline Goniotomy & \\
Mild hyphaema & $9 / 32(28 \%)$ \\
Total hyphaema & $2 / 32(6 \%)$ \\
Endophthalmitis & $1 / 32(3 \%)$ \\
Trabeculotomy & $1 / 57(2 \%)$ \\
Mild hyphaema & $1 / 57(2 \%)$ \\
Total hyphaema & $2 / 57(4 \%)$ \\
Flat AC & $7 / 77(9 \%)$ \\
Trabeculectomy & $1 / 77(1 \%)$ \\
Mild hyphaema & \\
Vitreous loss & \\
\hline
\end{tabular}

phobia $2 / 118$, cutaneous haemangioma $2 / 118$, and red eyes $1 / 118$.

The anterior segment abnormalities were grouped according to the classification of Hoskins $e a{ }^{18}$ based on data from the earliest examinations under anaesthesia where the iris and angle could be adequately visualised. These results and the other coexisting ocular abnormalities are summarised in Table 1 . Systemic problems diagnosed on presentation include two patients with ipsilateral Sturge-Weber syndrome involving both upper and lower lids, one patient with ipsilateral facial palsy and unilateral glaucoma, one patient with a club foot, and one patient with achondroplasia.

Presenting horizontal corneal diameter ranged from $11.5 \mathrm{~mm}$ to $15.0 \mathrm{~mm}$ with a mean of 13.2 (SD 0.9) $\mathrm{mm}$. Presenting IOP ranged from $3 \mathrm{~mm}$ $\mathrm{Hg}$ to $50 \mathrm{~mm} \mathrm{Hg}$ with a mean of 26.9 (SD 7.6) $\mathrm{mm} \mathrm{Hg}$. During the early 1980s, examination under anaesthesia was performed using nitrous oxide and oxygen and this accounted for 23/118 pretreatment examinations and was responsible for disparately low IOPs; 19 of these $23 \mathrm{had}$

for cumulative chance of success of each procedure. Success was defined as IOP $<21 \mathrm{~mm} \mathrm{Hg}$ on no treatment.

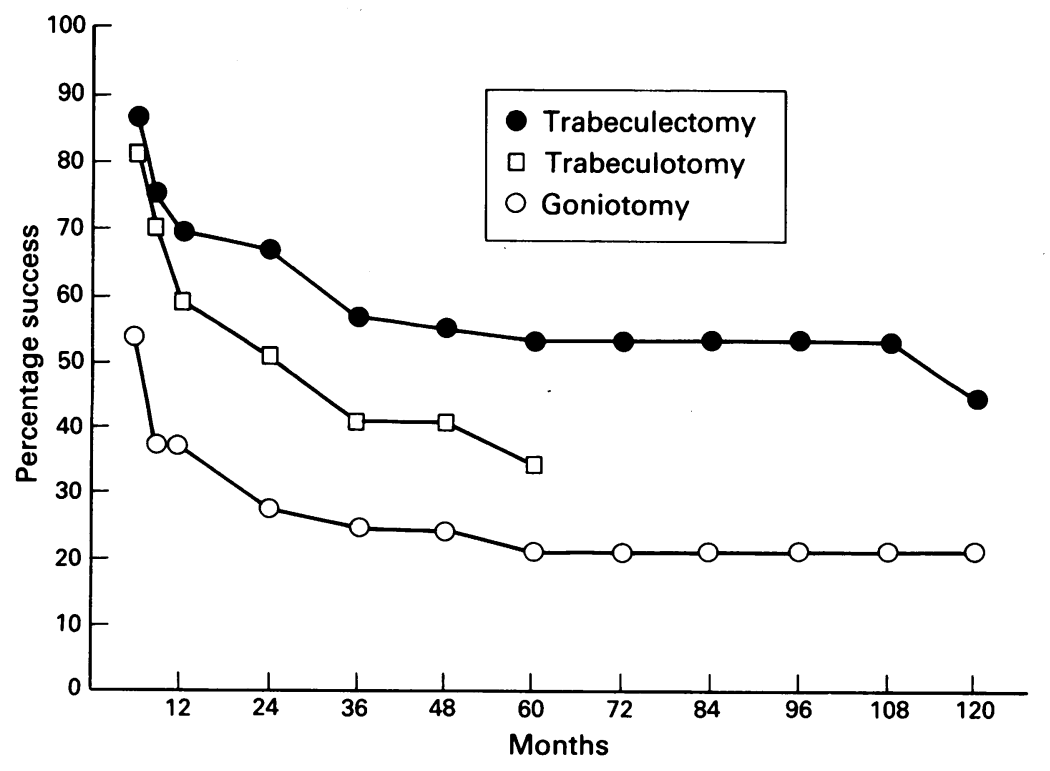

an IOP less than $21 \mathrm{~mm} \mathrm{Hg}$ at presentation. Ketamine became the agent of choice approximately 2 years into the study and was used diagnostically and for anaesthesia thereafter.

Of the 174 surgical procedures performed, there were 32 goniotomies, 57 trabeculotomies, 77 trabeculectomies, four cyclocryotherapies, two Molteno implants, one Scheie procedure, and one encircling band with anterior chamber tube shunt. The surgical complications of surgery are presented in Table 2 . One hyphaema after goniotomy required surgical removal and one flat anterior chamber after trabeculotomy required surgically reforming. In seven eyes Schlemm's canal was unable to be identified and trabeculotomy was not possible. In these eyes $(7 / 64,11 \%)$, the procedure was converted into a trabeculectomy. In two eyes $(2 / 57)$ the trabeculotome would only pass one way. Of the 118 eyes in the study group eight did not receive surgery; this was because of unexpected death, referral elsewhere, or being lost to follow up.

The initial procedure performed was trabeculotomy 45/110 (41\%), trabeculectomy 44/110 $(36 \%)$, and goniotomy $25 / 110(23 \%)$. Of these three main surgical procedures, the horizontal corneal diameter at the time of the procedure was not significantly different $(p<0.05)$ between the groups.

The decision as to which operation was performed depended on the surgeon's individual preference and the corneal clarity. Trabeculotomy was introduced in 1985 and therefore there is a maximum of 60 months of follow up. Goniotomy was considered the treatment of choice in this hospital in the early 1980s if the cornea was sufficiently clear, otherwise trabeculectomy was performed. However, by the late 1980 s, surgical preference was divided almost equally between the three major procedures. The results of these three procedures are presented in Figure 1 as a life table analysis of cumulative chance of success with this being defined as IOP $<21 \mathrm{~mm} \mathrm{Hg}$ on no treatment. Only $5 / 110$ were withdrawals because of unsatisfactory follow up.

Comparing trabeculectomy and goniotomy over the 120 months, there is a statistically significant difference between the two (MantelHaenszel procedure, $\left.\chi^{2}=11.964,1 \mathrm{df}, \mathrm{p}<0.001\right)$. However, there is no statistically significant difference between trabeculectomy and trabeculotomy up to the maximum follow up of 60 months (Mantel-Haenszel procedure, $\chi^{2}$ $=1.938,1 \mathrm{df}, \mathrm{p}>0.10$ ).

Ocular complications developing during the follow up period, unrelated to surgery, included four subluxed lenses, three bilateral cataracts, two retinal detachments, and two spontaneous perforations (the patients with Peter's anomaly and achondroplasia). Manifest nystagmus developed in $4 / 67(6 \%)$ of patients and squint developed in $5 / 67$. Occlusion was initiated in five patients (four convergent squints and one anisometropic patient) and improved the visual acuity in two patients.

Refractive errors greater than 2.0 dioptres or anisometropia greater than 1.5 dioptres spherical equivalent are presented in Table 3 for the subgroup of patients with follow up greater than 
Table 3 Significant refractive errors in patients with more than 36 months' follow up

\begin{tabular}{|c|c|}
\hline Patient & Refractive error \\
\hline 1 & $\begin{array}{l}-18.0 \mathrm{sph} \\
-16.0 \mathrm{sph}\end{array}$ \\
\hline 2 & $\begin{array}{r}-12.5 /-2.0 \times 180 \\
-7.5 /-1.5 \times 180\end{array}$ \\
\hline 3 & $\begin{array}{l}-8 \cdot 0 /-4 \cdot 0 \times 180 \\
-2 \cdot 5 /-1 \cdot 75 \times 170\end{array}$ \\
\hline 4 & $\begin{array}{l}-7.0 \mathrm{sph} \\
-0.5 \mathrm{sph}\end{array}$ \\
\hline 5 & $\begin{array}{l}-6.0 /-3.5 \times 55 \\
-1.0 \mathrm{sph}\end{array}$ \\
\hline 6 & $\begin{array}{l}-5.0 /-1.0 \times 90 \\
-1.5 /-1.0 \times 90\end{array}$ \\
\hline 7 & $\begin{array}{l}-8 \cdot 5 \mathrm{sph} \\
-8 \cdot 0 \mathrm{sph}\end{array}$ \\
\hline 8 & $\begin{array}{l}-4 \cdot 0 /-3.0 \times 140 \\
0.0 \mathrm{sph}\end{array}$ \\
\hline 9 & $\begin{array}{r}-2.5 /-2.5 \times 180 \\
0.0 /-4.0 \times 180\end{array}$ \\
\hline 10 & $\begin{array}{l}-2.0-1.5 \times 75 \\
0.0 \mathrm{sph}\end{array}$ \\
\hline 11 & $\begin{array}{l}-1.0 /-3.0 \times 145 \\
-0.5 /-3.0 \times 45\end{array}$ \\
\hline 12 & $\begin{array}{l}-1.0 /-1.0 \times 135 \\
0.0 \mathrm{sph}\end{array}$ \\
\hline 13 & $\begin{array}{r}+5.0 \mathrm{sph} \\
+1.5 \mathrm{sph}\end{array}$ \\
\hline 14 & $\begin{array}{l}+9.0 \mathrm{sph} \\
+9.0 \mathrm{sph}\end{array}$ \\
\hline 15 & $\begin{array}{r}+9.0 \mathrm{sph} \\
+10.0 \mathrm{sph} \\
+11.0 \mathrm{sph}\end{array}$ \\
\hline
\end{tabular}

36 months. Significant refractive errors occurred in $30 / 58(52 \%)$ of eyes, with $21 / 30(70 \%)$ being myopic. Two patients were aphakic following lensectomies and 12/31 (39\%) of patients had anisometropia greater than 1.5 dioptres.

A total of 460 examinations under anaesthesia were performed over the 10 year period, not including examinations at the time of surgery. The mean number of such examinations was 6.9 (SD 3.2) per patient and the mean number of operations per child was 1.6 (174/110). The review suggests that all examinations under anaesthesia were clinically indicated. There were no complications of anaesthesia.

Changes in horizontal corneal diameter were assessed in the subgroup of patients with more than 36 months of follow up. The mean presenting corneal diameter in this subgroup was 12.9 (SD $1 \cdot 1) \mathrm{mm}$ and ranged from $11.0 \mathrm{~mm}$ to $16.0 \mathrm{~mm}$. Thirty six months later the mean corneal diameter was 14.0 (SD 1.6) $\mathrm{mm}$ and ranged from $11.0 \mathrm{~mm}$ to $17.0 \mathrm{~mm}$. Three eyes showed a decrease in corneal diameter albeit only $0.5 \mathrm{~mm}$ in each case. The corneal diameter remained the same in 11/58 eyes and therefore a total of $14 / 58(24 \%)$ eyes did not have an increase in corneal diameter over the first $\mathbf{3 6}$ months of follow up. In general, the eyes with the least change in corneal diameter had the best control of IOP over the whole 36 month period.

The results of treatment at the end of the follow up period are summarised in Table 4. Satisfactory control of IOP was defined as being less than $21 \mathrm{~mm} \mathrm{Hg}$. Medical treatment consisted of timolol drops $0.25 \%$ twice daily in all patients. The patients with unsatisfactory control of the IOP were either in the process of having alterations in their medical management or were awaiting surgery. Eleven eyes had no perception of light and this included three patients in whom it was bilateral.

\section{Discussion}

Congenital glaucoma as a term is often used to include also infantile and juvenile glaucoma, but in this study it has been used in the strict sense of glaucoma diagnosed before 1 year of age. Furthermore, the patients are all Arabs with a high degree of consanguinity $(49 \%)$ and the surgeons involved are general ophthalmologists. However, the patients are similar to other reports with regard to characteristics on presentation. Glaucoma was unilateral in $28 \%$ compared with the usually quoted figure of $25 \% .{ }^{19}$ In the first 6 months of life, $78 \%$ of patients had presented compared with Anderson's 74\%. ${ }^{20}$ Corneal diameter at presentation was $13.2 \mathrm{~mm}$ compared with Scheie's patients with a mean of $12.8 \mathrm{~mm} .{ }^{21}$ Corneal haze was present in $75 \%$ of patients and this compares with the results of Costenbader $^{22}(70-88 \%)$. These data suggest that the results of surgical management should be comparable to other studies. The only real difference is that the patients are all Arabs and Debnath $e t \mathrm{al}^{14}$ has suggested that surgery is not as successful in this race.

Genetically, $13 \%$ of patients had a sibling affected but no patient had a parent or grandparent involved. Consanguinity was present in at
Table 4 Intraocular pressure at the end of the follow up period

Less than $21 \mathrm{~mm} \mathrm{Hg}$, no treatment

$\begin{array}{ll}\text { Less than } 21 \mathrm{~mm} \mathrm{Hg} \text {, no treatment } & 76(69 \%) \\ \text { Less than } 21 \mathrm{~mm} \mathrm{Hg} \text {, topical medical treatment } & 18(16 \%)\end{array}$

More than $21 \mathrm{~mm}$ Hg

Eyes requiring evisceration

$10(9 \%)$

$5(5 \%)$
$1(1 \%)$

$110(100 \%)$

least $49 \%$. This is consistent with either a single autosomal recessive gene ${ }^{23}$ or a multifactorial inheritance. ${ }^{24}$ The mean crude birth rate per year during the study period is estimated at $3.48 \% 25$ and therefore the incidence of congenital glaucoma is 1:8210 births; this is a little higher than Western societies but less than in Saudi Arabia.'

The IOP measurement is one of the key factors in the diagnosis and assessment of congenital glaucoma. General anaesthesia using nitrous oxide, oxygen, and halothane has been shown to decrease the IOP and the effect depends on the duration and depth of the anaesthesia ${ }^{826}$; however, ketamine does not affect the IOP measurement. Therefore it is unfortunate that during the first 2 years of this study nitrous oxide and oxygen were used for the examination under anaesthesia because this led to a delay in diagnosis and a delay in recognising surgical failure in a few children.

The diagnosis of trabeculodysgenesis in $94 \%$ of eyes seems high and, within the limitations of a retrospective study, it is probable that some of these eyes exhibited iridodysgenesis with anterior iris stromal defects of hypoplasia or hyperplasia. These would be particularly hard to diagnose with either limited experience or bilateral, subtle, symmetrical defects. However, Hoskins et al $^{18}$ state that 'most cases' of primary congenital glaucoma are isolated trabeculodysgenesis and that this is particularly so with the autosomal recessive genes. Only a prospective study will resolve this issue in these Arab children.

Goniotomy was the initial operation in only $23 \%$ of cases. In general, it was restricted to those patients with clearer corneas and no procedure was done 'blind'. However, only $53 \%$ of cases were successful for more than 3 months compared with an $81 \%$ success rate for trabeculotomy and $87 \%$ for trabeculectomy at the same time. This suggests that the trabecular meshwork was inadequately incised in half of the cases and this may reflect the surgical experience of the general ophthalmologists.

Trabeculotomy was a relatively safe procedure but Schlemm's canal could not be identified in $11 \%$ of eyes; this is similar to Harms ${ }^{9}$ experience (15\% not identified). Therefore it is recommended that the location and dimensions of the superficial scleral flap be such that it can be converted into a trabeculectomy if required.

Trabeculectomy has been the most successful procedure in these Arab children. There have been no cases of late endophthalmitis. At a follow up time of 9-12 months the success of trabeculectomy was $69 \%$ and this compares with Debnath's figures ${ }^{23}$ in Arab children of $54 \%$ with a mean follow up time of 11.2 months. However, 
IOP is only one criterion to judge success and corneal clarity, cup-disc ratio, visual acuity, visual field and an absence of cataract, amblyopia, and retinal detachment are also ultimately very important.

Strabismus was noted in only five patients and patching was initiated to treat amblyopia in four of these and one patient with anisometropia. Amblyopia can be a major obstacle to overcome in congenital glaucoma and is due to a combination of squint, corneal scarring, and anisometropia. ${ }^{27}$ While $80 \%(4 / 5)$ of the patients with squint received patching the incidence of squint is only $7 \%(5 / 67)$, and this contrasts with other studies in which the incidence varied from $15 \%{ }^{22}$ to $54 \% .{ }^{27}$ This, together with the incidence of anisometropia (39\%), suggests that amblyopia was much more common than was realised. If this is the case, then it has been because of the overreliance on examinations under anaesthesia and insufficient involvement of the orthoptist in the management of these cases.

The first objective in the management of congenital glaucoma is to reduce and maintain the IOP to within normal limits. In this regard trabeculectomy, as performed by general ophthalmologists on Arab children, is the most successful procedure over long periods of time.

The second objective in the management of these patients is to achieve adequate visual function in both eyes and this requires careful vigilance to detect and treat amblyopia. These children are at particular risk due to a combination of refractive errors, anisometropia, corneal opacities, and other ocular abnormalities.

1 Jaafar MS. Care of the infantile glaucoma patient. In: Reineck RD, ed. Ophthalmology annual. New York: Raven Press, 1988: 15.

2 Tabbara KF, Badr IA. Changing patterns of childhood blindness in Saudi Arabia. Br f Ophthalmol 1985; 69: 312-5.

3 Barkan O. Technique of goniotomy. Arch Ophthalmol 1938; 19: 7-223.
4 Barkan $O$. Goniotomy for the relief of congenital glaucoma. Brf Ophthalmol 1948; 32: 701-28.

5 Shaffer RN. Prognosis of goniotomy in primary infantile glaucoma (trabeculodysgenesis). Trans Am Ophthalmol Soc 1982; 80: 321-5

6 Broughton WL, Parks MM. An analysis of treatment of congenital glaucoma by goniotomy. Am $\mathcal{f}$ Ophthalmol 1981; 91: 566-72.

$7 \mathrm{McPherson}$ SD Jr, Berry DP. Goniotomy vs external trabeculotomy in developmental glaucoma. Am f Ophthalmol 1983; 95: 427-31.

8 Quigley HA. Childhood glaucoma: results with trabeculotomy and study of reversible cupping. Ophthalmology 1982; 89: and study. 26.

9 Harms H, Dannheim R. Epicritical consideration of 300 cases of trabeculotomy ab externo. Trans Ophthalmol Soc UK 1970; 89: 491-9.

10 Luntz MH, Livingston DG. Trabeculotomy ab-externo and trabeculectomy in congenital and adult-onset glaucoma. Am F Ophthalmol 1977; 83: 174-9.

11 Werther DE. Trabeculectomy in congenital glaucoma. Excerpta Medica 1979; 2: 1517-8.

12 Burke JP, Bowell R. Primary trabeculectomy in congenital glaucoma. $\mathrm{Br} \mathcal{F}$ Ophthalmol 1989; 73: 186-90.

13 Miller MH, Rice NSC. Trabeculectomy combined with $\beta$ irradiation for congenital glaucoma. Br f Ophthalmol 1991 75: 584-90.

14 Debnath SC, Teichmann KD, Salamah K. Trabeculectomy versus trabeculotomy in congenital glaucoma. $\mathrm{Br}$ Ophthalmol 1989; 73: 608-11.

15 Cairns JE. Trabeculectomy: preliminary report of a new method. Am f Ophthalmol 1968; 66: 673-9.

16 Elwood MJ. Causal relationships in medicine. A practical system for critical appraisal. Oxford: Oxford University Press, 1988. 296-307.

17 Kahn HA, Sempos CT. Statistical methods in epidemiology. Monographs in epidemiology and biostatistics. Vol 12. Oxford Monographs in epidemiology and biostatistics

18 Hoskins DH, Shaffer RN, Hetherington J. Anatomical classification of the developmental glaucomas. Arch Ophthalmol 1984; 104: 1331-6.

19 Kolker A, Hetherington J. Becker-Shaffer's diagnosis and therapy of the glaucomas. St Louis: Mosby, 1976,

20 Anderson JR. Hydrophthalmia or congenital glaucoma: its causes, treatment and cure. London: Cambridge University Press, 1939.

21 Scheie HG. The management of infantile glaucoma. $A M A$ Arch Ophthalmol 1959; 62: 35-54.

22 Costenbader FD, Kwitko M. Congenital glaucoma. An analysis of seventy-seven consecutive eyes. $\mathcal{F}$ Paediatr analysis of seventy-se

23 Duke-Elder S. System of ophthalmology. London: Kimpton, Vol 3, part 2, 548.

24 Merin S, Morin D. Heredity of congenital glaucoma. Br 7 Ophthalmol 1972; 56: 414-7.

25 United Nations Relief and Works Agency, Jerusalem. Data on file.

26 Haas JS. End results of treatment. Trans Am Acad Ophthalmol Otolaryngol 1955; 59: 333-40.

27 Rice NSC. Management of infantile glaucoma. $\mathrm{Br} \mathcal{F}$ Ophthalmol 1972; 56: 294-8. 